\title{
Ocorrência da brucelose e tuberculose bovina e percepção de riscos no Mato Grosso do Sul, Brasil*
}

\section{Occurrence of brucellosis and bovine tuberculosis and risk perception in Mato Grosso do Sul, Brazil}

\author{
Gilson Luiz Piva Filho', Ana Julia Silva e Alves², Laurêncio Garcia Carvalho³, Marcia Marinho, \\ Luzia Helena Queiroz ${ }^{1,4 * *}$
}

RESUMO: Determinar a ocorrência da brucelose, da tuberculose e a percepção de riscos acerca de ambas as zoonoses foi o objetivo do estudo em rebanhos bovinos leiteiros do município de Paranaíba, Mato Grosso do Sul, Brasil. As visitas ocorreram entre novembro de 2012 e março de 2013, em 42 propriedades georreferenciadas, nas quais foram aplicados questionários aos produtores e realizadas as coletas de sangue para testes sorológicos e de tuberculinização. A ocorrência de focos, tanto da brucelose quanto da tuberculose, nas propriedades foi de 2,38\% (1/42), porém, há um baixo conhecimento dos produtores sobre os fatores de risco para essas doenças.

PALAVRAS-CHAVE: brucelose bovina; percepção de risco; tuberculose bovina; zoonoses.

\begin{abstract}
The aim of these study was to determine the occurrences of brucellosis and bovine tuberculosis, and the perception of dairy farmers on the risk of these diseases in dairy cattle herds in the municipality of Paranaíba, Mato Grosso do Sul state, Brazil. The total of 42 properties were visited for the application of a questionnaire to dairy farmers, and blood sample collection for serological and tuberculin test, from November 2012 to March 2013. The occurrence of outbreaks, both of brucellosis and tuberculosis, in the properties was $2.38 \%(1 / 42)$. The data showed deficiency in risk perception of these diseases on the part of the farmers.
\end{abstract}

KEYWORDS: bovine brucellosis; risk perception; bovine tuberculosis; zoonosis.

\footnotetext{
*Dissertação de Mestrado de Gilson Luiz Piva Filho pelo Programa de Pós-graduação em Ciência Animal da Faculdade de Medicina Veterinária de Araçatuba, Universidade Estadual Paulista "Júlio de Mesquita Filho".

'Programa de Pós-graduação em Ciência Animal, Faculdade de Medicina Veterinária de Araçatuba, Universidade Estadual Paulista “Júlio de Mesquita Filho” (UNESP) - Araçatuba (SP), Brasil.

${ }^{2}$ Programa de Pós-graduação em Epidemiologia Experimental Aplicada às Zoonoses, Faculdade de Medicina Veterinária, Universidade de São Paulo (FMVZ/USP) São Paulo (SP), Brasil.

${ }^{3}$ Agência Estadual de Defesa Sanitária Animal e Vegetal - Paranaíba (MS), Brasil.

${ }^{4}$ Departamento de Apoio, Produção e Saúde Animal, Faculdade de Medicina Veterinária de Araçatuba, UNESP - Araçatuba (SP), Brasil.

**Autor correspondente: luziahqueiroz@gmail.com, Ihqueiroz@fmva.unesp.br

Recebido em: 28/06/2016. Aceito em: 11/10/2017
} 
A brucelose e a tuberculose bovina classificam-se como enfermidades infectocontagiosas graves, de etiologia bacteriana, cuja prevalência junto aos rebanhos bovinos do Brasil tem sido melhor caracterizada a partir de 1998 com levantamentos de prevalência realizados em vários estados (POESTER et al., 2009; FERREIRA NETO et al., 2016). Ambas geram consequências econômicas desastrosas para pecuaristas, devido em grande parte à aquisição de animais doentes. A queda na produçâo de leite e carne; a desvalorização dos animais; um maior intervalo entre partos, abortos, nascimentos de bezerros fracos, que podem morrer logo após o nascimento, retenção de placenta e metrites são consequências dessas enfermidades (CFSPH, 2007; LAGE et al., 2008, POESTER et al., 2013). Com base nos índices de prevalência obtidos em vários estados do Brasil, as perdas econômicas no país devido à brucelose bovina foram estimadas em R \$ 892 milhôes, equivalentes a U \$ 448 milhóes (SANTOS et al., 2013).

Em levantamento epidemiológico realizado no Brasil no ano de 1998 , a prevalência média nacional era de $1,3 \%$ para tuberculose bovina e de 4,0 a 5,0\% para brucelose bovina, sendo que o Mato Grosso do Sul (MS) apresentou, nesse mesmo ano, uma prevalência para brucelose de 6,3\% (BRASIL, 2006). Contudo, nos últimos diagnósticos de situação da brucelose no estado sul mato-grossense realizados em 1998 (CHATE et al., 2009) e 2009 (LEAL FILHO et al., 2016), observou-se uma queda na prevalência de focos de 41,5 para $30,6 \%$. Considerando apenas a regiáo onde se localiza o rebanho leiteiro e, mais especificamente, o município de Paranaíba, houve uma queda na prevalência de focos de 28,5 para $14,8 \%$.

Com relaçáo à tuberculose bovina, ROXO (2004) estimou a prevalência de $0,37 \%$ para a regiáo Centro-Oeste brasileira. No ano de 2009, a porcentagem de focos no estado do MS foi de $1,30 \%$, e na regiáo do Planalto Norte, onde se localiza o município de Paranaíba, foi de 0,61\%. Não existem, porém, estudos focados nas criaçóes leiteiras do município de Paranaíba, MS, ou de sua microrregiāo, considerando que esse município é o maior produtor de leite do estado (IBGE, 2010).

O objetivo desta pesquisa foi estudar a prevalência da brucelose e da tuberculose bovina em rebanhos leiteiros e a percepçáo dos produtores de leite sobre o risco dessas enfermidades para a saúde pública, no município de Paranaíba, MS.

O material de estudo foi obtido no município de Paranaíba, situado na regiáo leste do MS, que, segundo o Instituto Brasileiro de Geografia e Estatística (IBGE, 2010), corresponde à regiáo de maior produçáo de leite do estado, com mais de 33.497 mil litros por dia. Foram visitadas 42 propriedades, escolhidas por conveniência por serem credenciadas na associação de produtores de leite do município. A área total das propriedades totalizou 5.272 hectares e todas foram georreferenciadas por meio do Global Positioning System (Garmin eTrex 20, Garmin Ltd, Taiwan) (Fig. 1).

Durante as visitas, foi aplicado um questionário aos produtores com o objetivo de identificar falhas no manejo sanitário e o grau de conhecimento deles sobre a tuberculose e a brucelose bovina. Posteriormente, os proprietários foram orientados sobre prevenção, controle e notificaçáo de casos suspeitos de brucelose e tuberculose bovina, quando assinaram um termo de consentimento livre e esclarecido, comprometendo-se em acatar a medida de abate dos animais positivos.

De um total de 3.843 animais das propriedades, 1.889 $(49,1 \%)$ eram vacas em lactação, de raças puras, com predominância da raça holandesa ou cruzadas, com idade acima de 24 meses e vacinadas para brucelose entre 3 e 8 meses de idade, das quais foram colhidas 378 amostras de sangue, correspondendo a $20 \%$ do rebanho. Os soros foram imediatamente submetidos ao teste com Antígeno Acidificado Tamponado (AAT) e os reagentes confirmados pelo teste 2-mercaptoetanol (2-ME) para brucelose. Para tuberculose, utilizou-se o teste cervical simples (TCS) para triagem e o teste cervical comparativo (TCC) como confirmatório (BRASIL, 2006). As porcentagens foram obtidas com intervalo de confiança de 95\% (IC95\%) e nível de significância de 5\%. Para os cálculos estatísticos foi utilizado o programa Epi Info versão 7.2, e para a construçáo do mapa de localizaçáo das propriedades, o programa QGIS $^{\bullet}$ versão 2.18.11.

Dentre as 378 vacas submetidas ao diagnóstico de brucelose, apenas $1(0,26 \%$; IC95\% 0,05-1,48) se apresentou reagente, com resultado positivo tanto no teste de triagem quanto nos testes confirmatórios, o que resultou numa ocorrência nos rebanhos amostrados de 2,38\% (1/42) com IC95\% 0,06-12,57. Essa porcentagem está dentro da faixa de variaçáo da prevalência no rebanho brasileiro, que oscilou entre 0,91 e 30,60\% no período de 2009 a 2014 (FERREIRA NETO et al., 2016). Considerando apenas a regiáo do MS e o rebanho leiteiro no extrato ao qual pertence o município de Paranaíba, os resultados obtidos estáo abaixo da prevalência de focos observados em 1998 (CHATE et al., 2009) e 2009 (LEAL FILHO et al., 2016), que foi de 28,7 e $14,8 \%$, respectivamente.

Para a tuberculose, a ocorrência dentre os animais também foi de $0,26 \%$ (1/378) e nos rebanhos, de 2,38\% (1/42), com IC95\% 0,06-12,57. A prevalência média nacional da tuberculose bovina entre 1989 e 1998 foi de 1,3\% de animais infectados (BRASIL, 2006). Um levantamento realizado em 2009 no MS revelou prevalência de 1,3\% nos rebanhos do estado e de 1,6\% nos rebanhos leiteiros na regiáo do Planalto Norte, onde se localiza Paranaíba (GUEDES et al., 2016).

O número de vacas em lactação nas propriedades estudadas variou entre 16 e 75 (média 45), criadas de forma extensiva e intensiva, em 52,4 e 46,7\% das propriedades, respectivamente. O perfil dos produtores leiteiros (Tabela 1) assemelha-se, em alguns aspectos, ao perfil observado nos rebanhos leiteiros de Minas Gerais (BELCHIOR et al., 2016), uma vez que $73,8 \%(31 / 42)$ trabalham com apenas uma ordenha por dia, $57,1 \%$ (24/42) utilizam-se do método manual de ordenha e $42,9 \%$ (18/42) armazenam o leite em latôes, não utilizando a 


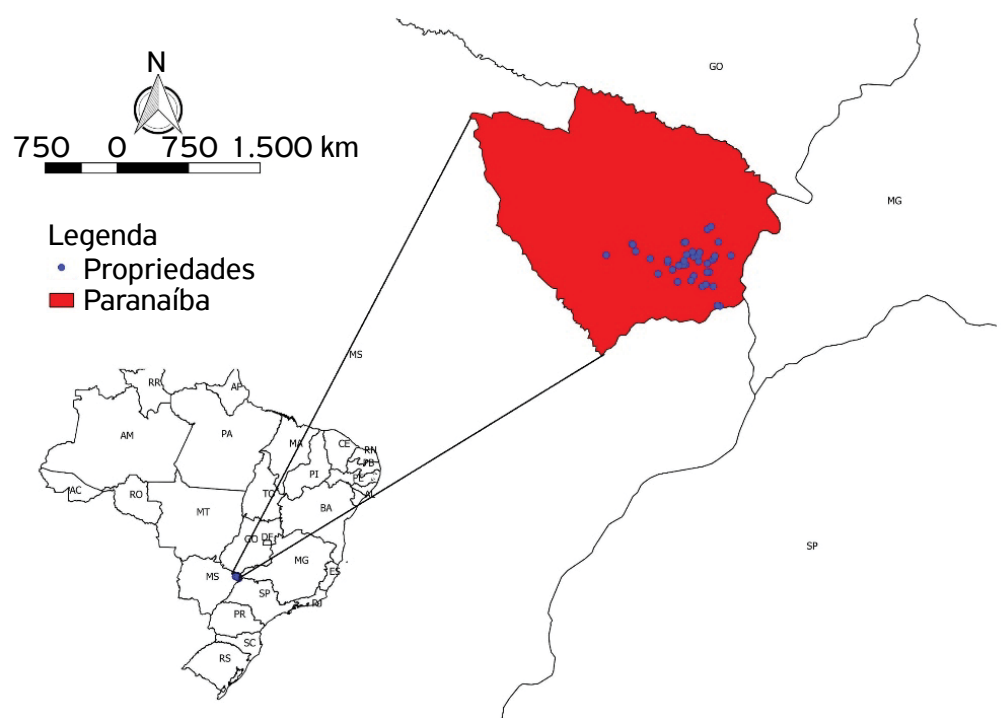

Figura 1. Localização das propriedades amostradas do município de Paranaíba, Mato Grosso do Sul.

Tabela 1. Variáveis avaliadas por questionário aplicado aos produtores de leite do município de Paranaíba, Mato Grosso do Sul, Brasil, e seus respectivos resultados.

\begin{tabular}{|c|c|c|c|c|}
\hline Perguntas & Variáveis & $\mathbf{n}$ & $\%$ & IC95\% \\
\hline \multirow{2}{*}{ Forma de criação } & Extensiva & 22 & 52,4 & $36,4-68,0$ \\
\hline & Intensiva & 20 & 47,6 & $32,0-63,6$ \\
\hline \multirow{2}{*}{ Número de ordenhas por dia } & $1 \mathrm{vez}$ & 31 & 73,8 & $58,0-86,1$ \\
\hline & 2 vezes & 11 & 26,2 & $13,7-42,0$ \\
\hline \multirow{3}{*}{ Forma de ordenha } & Manual & 20 & 47,6 & $32,0-63,6$ \\
\hline & Mecanizada com balde ao pé & 15 & 35,7 & $21,6-52,0$ \\
\hline & Mecanizada canalizada & 7 & 16,7 & $7,0-32,4$ \\
\hline \multirow{2}{*}{ Forma de acondicionamento do leite } & Latões & 18 & 42,9 & $27,7-59,0$ \\
\hline & Tanques resfriadores & 24 & 57,1 & $41,0-72,3$ \\
\hline \multirow{3}{*}{ Destino do leite produzido } & Laticínios inspecionados & 31 & 73,8 & $58,0-86,1$ \\
\hline & Venda direta ao consumidor & 5 & 11,9 & $4,0-25,6$ \\
\hline & Queijo artesanal & 6 & 14,3 & $5,4-28,5$ \\
\hline \multirow{2}{*}{ Forma de consumo do leite na propriedade } & Cru (in natura) & 28 & 66,7 & $50,4-80,4$ \\
\hline & Fervido & 14 & 33,3 & $19,6-49,5$ \\
\hline \multirow{2}{*}{ Conhecimento de doenças transmitidas pelo leite para o homem } & Sim & 14 & 35,7 & $21,5-52,0$ \\
\hline & Não & 39 & 64,3 & $48,0-78,4$ \\
\hline \multirow{2}{*}{ Histórico de abortamento e problemas de parto nas vacas } & Sim & 5 & 11,9 & $4,0-25,6$ \\
\hline & Não & 37 & 88,1 & $74,4-96,0$ \\
\hline \multirow{2}{*}{ Utilização de piquete de parição (maternidade) } & Sim & 20 & 47,6 & $32,0-63,6$ \\
\hline & Não & 22 & 52,4 & $36,4-68,0$ \\
\hline \multirow{2}{*}{ Utilização de piquete de quarentena } & Sim & 8 & 19,0 & $8,6-34,1$ \\
\hline & Não & 34 & 81,0 & $65,9-91,4$ \\
\hline \multirow{2}{*}{ Criações consorciadas com o rebanho bovino } & Sim & 29 & 69,0 & $52,9-82,4$ \\
\hline & Não & 13 & 31,0 & $17,6-46,1$ \\
\hline \multirow{2}{*}{ Utilização de EPI } & Sim & 6 & 14,3 & $5,4-22,5$ \\
\hline & Não & 36 & 85,7 & $71,5-94,6$ \\
\hline \multirow{2}{*}{$\begin{array}{l}\text { Conhecimento do PNCEBT e realização dos testes } \\
\text { de diagnóstico }\end{array}$} & Sim & 7 & 16,7 & $7,0-31,4$ \\
\hline & Não & 35 & 83,3 & $68,6-98,0$ \\
\hline \multirow{3}{*}{ Manejo na reprodução } & Monta natural & 25 & 59,5 & $43,3-74,4$ \\
\hline & Inseminação artificial & 2 & 4,8 & $0,6-16,2$ \\
\hline & Monta natural + inseminação artificial & 15 & 35,7 & $21,6-52,0$ \\
\hline
\end{tabular}

IC95\%: intervalo de confiança de 95\%; EPI: equipamento de proteção individual; PNCEBT: Programa Nacional de Controle e Erradicação da Brucelose e Tuberculose. 
refrigeração, características que demostram uma baixa tecnificação da produção leiteira. $\mathrm{O}$ tamanho do rebanho leiteiro e a forma de criação são fatores de risco para a disseminaçáo da brucelose bovina (MOTA et al., 2016; OLIVEIRA et al., 2013) e, dessa forma, o pequeno número de fêmeas em lactação nas propriedades aliado à pratica de vacinaçáo delas contra brucelose poderia justificar a baixa ocorrência da doença nas propriedades amostradas.

$\mathrm{Na}$ maioria das propriedades $(73,8 \%)$ o leite era destinado para laticínios, do município ou da região, totalizando 12.740 litros de leite por dia, enquanto em 26,2\% (11/42) os proprietários afirmaram destinar seus produtos à venda informal, in natura, geralmente engarrafados em garrafas plásticas ou sob a forma de queijo artesanal, para a população do município, totalizando 1.890 litros de leite por dia. O comércio in natura foi representativo nas propriedades amostradas, quando comparado com o observado em Minas Gerais, onde apenas 9,4\% das propriedades realizam venda direta (BELCHIOR et al., 2016). FIGUEIREDO et al. (2008) destacaram que, mesmo nos rebanhos tecnificados, o leite muitas vezes é distribuído in natura para o consumo humano, e essa é uma preocupação com a saúde pública, pois, em muitos casos os animais podem ser positivos para tuberculose, como ocorreu em $6,7 \%$ dos rebanhos que vendiam leite direto ao consumidor em Minas Gerais (BELCHIOR et al., 2016). Mesmo que o leite in natura seja utilizado para a produçáo de queijo, ainda pode haver a presença desses agentes, como foi o caso da detecção de Brucella abortus em queijos no Pará, Amapá e Rondônia (SILVA et al., 2016).

O consumo de leite nas propriedades também foi um fator de destaque, pois $28(66,7 \%)$ proprietários afirmam consumir o leite cru e apenas $14(33,3 \%)$ disseram que o consumo é feito após fervura, demonstrando a vulnerabilidade e o risco de infecçáo desses produtores, uma vez que a grande maioria dos entrevistados $(92,9 \%)$ desconhece as doenças passíveis de transmissão para o homem pelo leite, como a brucelose e a tuberculose. Segundo POESTER et al. (2002), a brucelose é considerada uma antropozoonose crônica e uma ameaça silenciosa para os seres humanos porque a sua ocorrência está subestimada devido à falta de serviços de comunicação e diagnóstico adequado em animais e humanos. Náo foi relatada a ocorrência dessas zoonoses entre os proprietários entrevistados, entretanto, em outras regiōes leiteiras tradicionais do Brasil foram descritos casos de tuberculose humana em propriedades com bovinos positivos (BELCHIOR et al., 2016).

Do rebanho avaliado, 11,9\% (05/42) das fêmeas apresentaram histórico de abortamentos e problemas durante o parto, principalmente a retenção de placenta. Entre elas, a propriedade foco de brucelose identificou a fêmea soropositiva com problemas de cria e de queda de produçáo leiteira. Um total de $81 \%$ dos produtores relatou que não utiliza piquete para quarentena de animais e menos da metade $(42,9 \%)$ utiliza piquete maternidade. Essas variáveis, entretanto, não foram consideradas como fatores de risco para ambas as doenças (MOTA et al., 2016; OLIVEIRA et al., 2013; BELCHIOR et al., 2016) e também não influenciaram na sua baixa ocorrência no município de Paranaíba.

Embora os proprietários pratiquem a vacinação das fêmeas entre 3 e 8 meses de idade, $83 \%$ afirmaram desconhecer o Programa Nacional de Controle e Erradicação da Brucelose e Tuberculose (PNCEBT) e também nunca realizaram exames para diagnóstico dessas doenças, nem mesmo para aquisição de novos animais. OLIVAL et al. (2009) relataram uma porcentagem ainda maior $(98,8 \%)$ de produtores de leite entrevistados do município de Carlinda, Mato Grosso (MT), que desconheciam o PNCEBT, e FERNANDES et al. (2012) mostraram que apenas $5,9 \%$ dos produtores entrevistados de Itapetinga, Bahia, realizam o teste de tuberculina nos animais introduzidos na propriedade. O comércio de animais sem exigência de controle sanitário foi apontado como um importante fator de risco para introdução tanto da brucelose (ALVES et al., 2009; MOTA et al., 2016; OLIVEIRA et al., 2013) quanto da tuberculose (BELCHIOR et al., 2016).

A criação consorciada foi observada em $69 \%$ das propriedades analisadas, sendo que suínos, equinos, aves e cães estavam presentes em todas essas localidades, e que em $20,7 \%$ dessas os bovinos eram criados juntamente com caprinos. A criaçấo de caprinos quando consorciada com bovinos e o aleitamento desses com o leite de vaca são fatores de risco para transmissão da tuberculose aos caprinos, e ambas as espécies são importantes para a transmissão dessa doença ao homem (MELO et al., 2012). A criação conjunta com equinos foi apontada como uma das variáveis associadas à ocorrência da brucelose em bovinos de propriedades rurais de agricultura familiar do Agreste Paraibano (OLIVEIRA et al., 2013).

A grande maioria dos entrevistados $(85,7 \%)$ afirmou náo utilizar o mínimo necessário de equipamentos de proteção individual (EPI) ao manipular carcaças, abortos e secreçōes biológicas. Em 59,5\% das propriedades adota-se a monta natural seguida pela inseminação artificial associada com monta natural $(35,7 \%)$, e uma pequena porcentagem $(4,8 \%)$ trabalha apenas com inseminação artificial. $\mathrm{O}$ tipo de prática reprodutiva baseada em inseminação artificial, assim como a presença de assistência veterinária, foram considerados fatores protetores para ocorrência de brucelose (MOTA et al., 2016).

Neste trabalho foi possível verificar a baixa ocorrência de tuberculose e brucelose no rebanho bovino leiteiro amostrado, embora haja uma grande desinformaçáo por parte dos produtores sobre medidas de manejo sanitário e fatores de risco associados à sua ocorrência. Assim, ressaltamos a necessidade de maior envolvimento do setor público com a comunidade e os veterinários de campo, na divulgaçáo de informaçôes aos produtores leiteiros do município, buscando a adoção de outras medidas além da vacinação, que impeçam a introdução dessas doenças nos rebanhos leiteiros do município de Paranaíba, MS. 
ALVES, A.J.S.; GONÇALVES, V.S.P.; FIGUEIREDO, V.C.F.; LÔBO, J.R.; BAHIENSE, L.; AMAKU, M.; FERREIRA, F.; FERREIRA NETO, J.S.; DIAS, R.A. Situação epidemiológica da brucelose bovina no Estado da Bahia. Arquivo Brasileiro de Medicina Veterinária e Zootecnia, v.61, S1, p.6-13, 2009.

BELCHIOR, A.P.C.; LOPES, LB.; GOLÇALVES, V.S.P.; LEITE, R.C. Prevalence and risk factors for bovine tuberculosis in Minas Gerais State, Brazil. Tropical Animal Health and Production, v.48, p.373-378, 2016.

BRASIL. Ministério da Agricultura, Pecuária e Abastecimento. Programa Nacional de Controle e Erradicação da Brucelose e da Tuberculose -(PNCEBT): Manual técnico. Brasília: MAPA, 2006. 184p.

CENTER FOR FOOD SECURITY \& PUBLIC HEALTH (CFSPH). Bovine Brucellosis: Brucella abortus. Animal Disease Factsheets. College of Veterinary Medicine, Ames, 2007. Disponível em: <http:// www.cfsph.iastate.edu/Factsheets/pdfs/brucellosis_abortus. pdf>. Acesso em: 17 maio 2013.

CHATE, S.C.; DIAS, R.A.; AMAKU, M.; FERREIRA, F.; MORAES, G.M.; COSTA NETO, A.A.; MONTEIRO, L.A.R.C.; LÔBO, J.R.; FIGUEIREDO, V.C.F.; GONÇALVES, V.S.P.; FERREIRA NETO, J.S. Situação epidemiológica da brucelose bovina no estado do Mato Grosso do Sul. Arquivo Brasileiro de Medicina Veterinária e Zootecnia, v.61, S1, p.46-55, 2009.

FERNANDES, S.A.A.; FALEIRO, A.S.; FERRÃO, S.P.B.; VIEIRA, V.F.; SOUZA, D.R.; NUNES, L.R.; SANTOS, N.B.L.; FERRÃO, I.S.; PEREIRA, M.M.; FREITAS, M.A.; MATARAZZO, S.V. Perfil tecnológico de sistemas de produção de leite resfriado. Revista Brasileira de Saúde e Produção Animal, v.13, n. 1, p.1-12, 2012.

FERREIRA NETO, J.S.; SILVEIRA, G.B.; ROSA, B.M.; GONÇALVES, V.S.P.; GRISI-FILHO, J.H.H.; AMAKU, M.; DIAS, R.A.; FERREIRA, F.; HEINEMANN, M.B.; TELLES, E.O.; LAGE, A.P. Analysis of 15 years of the National Program for the Control and Eradication of animal Brucellosis and Tuberculosis, Brazil. Semina: Ciências Agrárias, v.37, n.5, S2, p.3385-3402, 2016.

FIGUEIREDO, E.E.S.; SILVA, M.G.; FONSECA, L.S.; SILVA, J.T.; PASCHOALIN, V.M.F. Detecção do complexo Mycobacterium tuberculosis no leite pela Reação em Cadeia da Polimerase seguida de análise de Restrição do Fragmento Amplificado (PRA). Ciência Animal Brasileira, v.9, n.4, p.1023-1033, 2008.

GUEDES, I.B.; BOTTENE, I.F.N.; MONTEIRO, L.A.R.C.; LEAL FILHO, J.M.; HEINEMANN, M.B.; AMAKU, M.; GRISI-FILHO, J.H.H.; DIAS, R.A.; FERREIRA, F.; TELLES, E.O.; GONÇALVES, V.S.P.; FERREIRA NETO, J.S. Prevalence and risk factors for bovine tuberculosis in the state of Mato Grosso do Sul, Brazil. Semina: Ciências Agrárias, v.37, n.5, S2, p.3579-3588, 2016.

INSTITUTO BRASILEIRO DE GEOGRAFIA E ESTATÍSTICA (IBGE). Primeiros dados do Censo 2010. Rio de Janeiro: IBGE, 2010. Disponível em: <http://www.ibge.gov.br/cidadesat/xtras/perfil. php?codmun $=500630>$. Acesso em: 25 mar. 2013.

LAGE, A.P.; POESTER, F.P.; PAIXÃO, T.A.; SILVA, T.M.A.; XAVIER, M.N.; MINHARRO, S.; MIRANDA, K.L.; ALVES, C.M.; MOL, J.P.S.;
SANTOS, R.L. Brucelose bovina: uma atualização. Revista Brasileira de Reprodução Animal, v.32, n.3, p.202-212, 2008.

LEAL FILHO, J.M.; BOTTENE, I.F.N.; MONTEIRO, L.A.R.C.; PELLEGRIN, A.O.; GONÇALVES, V.S.P.; FERREIRA, F.; DIAS, R.A.; AMAKU, M.; TELLES, E.O.; GRISI-FILHO, J.H.H.; HEINEMANN, M.B.; FERREIRA NETO, J.S. Control of bovine brucellosis from 1998 to 2009 in the state of Mato Grosso do Sul, Brazil. Semina: Ciências Agrárias, v.37, n.5, S2, p.3467-3478, 2016.

MELO, L.E.H.; MOTA, R.A.; MAIA, F.C.L.; FERNANDES, A.C.C.; SILVA, T.I.B.; LEITE, J.E.B.; BAPTISTA FILHO, L.C.F.; RAMOS, C.A.N. Ocorrência e caracterização da tuberculose em caprinos leiteiros criados no estado de Pernambuco. Pesquisa Veterinária Brasileira, v.32, n.9, p.831-837, 2012.

MOTA, A.L.A.A.; FERREIRA, F.; FERREIRA NETO, J.S.; DIAS, R.A.; AMAKU, M.; HILDEBRAND GRISI-FILHO, J.H.; TELLES, E.O.; PICÃO GONÇALVES, V.S. Large-scale study of herd-level risk factors for bovine brucellosis in Brazil. Acta Tropica, v. 164, p.226-232, 2016.

OLIVAL, A.A.; SPEXOTO, A.A.; DIAS, R.A.; PINHEIRO, S.R. Avaliação de um programa educativo de rádio sobre tuberculose bovina no município de Carlinda, MT: resultados, efeitos e impactos. Veterinária e Zootecnia, v. 161, n.3, p.533-545, 2009.

OLIVEIRA, R.M.; SILVA, M.L.C.R.; MACÊDO, M.M.S.; HIGINO, S.S.S.; PAULIN, L.M.; ALVES, C.J.; CARVALHO, M.G.X.; AZEVEDO, S.S. Soroepidemiologia da leptospirose e brucelose em propriedades rurais de agricultura familiar do agreste paraibano, Nordeste do Brasil. Arquivos do Instituto Biológico, São Paulo, v.80, n.3, p.303-311, 2013.

POESTER, F.P.; FIGUEIREDO, V.C.F.; LÔBO, J.R.; GONÇALVES, V.S.P.; LAGE, A.P.; ROXO, E.; MOTA, P.M.P.C.; MÜLLER, E.E.; FERREIRA NETO, J.S. Estudos de prevalência da brucelose bovina no âmbito do Programa Nacional de Controle e Erradicação de Brucelose e Tuberculose: Introdução. Arquivo Brasileiro de Medicina Veterinária e Zootecnia, v.61, supl. 1, p.1-5, 2009.

POESTER, F.P.; GONÇALVES, V.S.P.; LAGE, A.P. Brucellosis in Brazil. Veterinary Microbiology, v.90, p.55-62, 2002.

POESTER, F.P.; SAMARTINO, L.E.; SANTOS, R.L. Pathogenesis and Pathobiology of brucellosis in livestock. Revue scientifique et technique (International Office of Epizootics), v.32, n. 1, p.105-1 15, 2013.

ROXO, E. Situação Atual da Tuberculose Bovina no Brasil. Programa Nacional de Controle e Erradicação de Brucelose e Tuberculose Animal, São Paulo, p.1-5, 2004.

SANTOS, R.L.; MARTINS, T.M.; BORGES, A.M.; PAIXÃO, T.A. Economic losses due to bovine brucellosis in Brazil. Pesquisa Veterinária Brasileira, v.33, n.6, p.759-764, 2013.

SILVA, J.; MORAES, C.M.; SILVA, C.L.; SALES, G.A.; KEID, L.B.; MATOS, P.C.M.; LARA, A.P.S.S.; MORAES, C.C.G. Brucella abortus detected in cheese from the Amazon region: differentiation of a vaccine strain (B19) from the field strain in the states of Pará, Amapá and Rondônia, Brazil. Pesquisa Veterinária Brasileira, v.36, n.8, p.705-710, 2016. 